\title{
Directed Deposition of Nickel Nanoparticles Using Self-Assembled Organic Template
}

\author{
András Paszternák, ${ }^{1,2}$ Meital Shviro, ${ }^{1}$ Lajos Nyikos, ${ }^{2}$ and David Zitoun ${ }^{1}$ \\ ${ }^{1}$ Department of Chemistry and Bar Ilan Institute of Nanotechnology and Advanced Materials (BINA), \\ Bar-Ilan University, 52900 Ramat Gan, Israel \\ ${ }^{2}$ Institute of Materials and Environmental Chemistry, Research Centre for Natural Sciences, Hungarian Academy of Sciences, \\ Budapest 1117, Magyar Tudósok Körútja 2, Hungary
}

Correspondence should be addressed to András Paszternák; paszternak.andras@ttk.mta.hu

Received 25 July 2014; Revised 22 September 2014; Accepted 6 October 2014; Published 23 October 2014

Academic Editor: Shadi A. Dayeh

Copyright ( 2014 András Paszternák et al. This is an open access article distributed under the Creative Commons Attribution License, which permits unrestricted use, distribution, and reproduction in any medium, provided the original work is properly cited.

\begin{abstract}
Self-assembled organic monolayers are useful templates for nanofabrication. Ordered layer of long alkyl-chain molecules can direct the wet chemical deposition of metallic coatings on different substrates. Ordered structures of fatty acids and their motions on the phenyloctane/HOPG interface are observed by scanning tunneling microscopy (STM). Modification of self-assembled fatty acid patterns due to hydroxamic acid presence is also in the focus of the research. Fatty acid layer formation, the structure of the formed thin film on solid/liquid interface, and simultaneous nickel colloidal deposition have been investigated.
\end{abstract}

\section{Introduction}

Ordered metallic structures can be created by simultaneous self-assembly of a molecular monolayer and wet chemical metal deposition. 2D nanoparticle arrays assembled on a surface may exhibit electronic, optical, and sensing properties and can be used to create a variety of electronic and sensor components [1]. The STM is a powerful tool to obtain information on the molecular arrangement and orientation at an atomic scale. Layer formation of different fatty acid, its derivatives, and mixtures on solid/liquid interface has been investigated by this means [2-5]. Fatty acids are typically hydrogen-bonding compounds. The carboxylic acid groups form dimers and the molecular axis is perpendicular to the lamella axis, irrespective of the length of the alkyl chain [6]. The interaction between the alkyl-chain and the substrate is responsible for the perfect alignment of the molecules and the stability of the layer. Under STM observation, specific chemical groups [7-9] provide different contrast in the tunneling current. STM provides even submolecular resolution and different models are found in the literature to explain the molecular organization at the solid-liquid interface [10]. Hibino et al. [11] have found that fatty acids with a longer alkyl chain adsorb preferentially on the graphite substrate by the investigation of binary mixtures of myristic $\operatorname{acid}\left(\mathrm{C}_{13} \mathrm{H}_{27} \mathrm{COOH}\right)$ and behenic acid $\left(\mathrm{C}_{21} \mathrm{H}_{43} \mathrm{COOH}\right)$ using STM. The long axis of the molecules lies in the plane of the graphite substrate and alkyl chains of the neighboring molecules stand parallel to each other. The chemical conformation is driven by the intermolecular interactions and surface interactions. The same research group [12] has also shown the odd-even effect in monolayer of fatty acids formed on a graphite surface. Layers of fatty acids with an even number of carbon atoms consist of two kinds of molecular arrangements that are mirror images of each other, while those with an odd number of carbon atoms only exhibit one type of arrangement consisting of a racemic mixture of two dimer types that are opposite enantiomers in two dimensions. The odd-even effect takes place as a result of the short-range interactions between the alkyl-chains. Oddeven effect was also studied by Wintgens et al. [13] and Tao [14]. X-ray and neutron diffraction have been used to investigate the formation of solid crystalline monolayers of linear carboxylic acids by Bickerstaffe et al. [15] It was 
concluded that the monolayer structures determined by STM for the longer acid homologues adsorbed on graphite from solution are in good agreement with those determined using $\mathrm{X}$-ray and neutron diffraction for the shorter homologues. STM was used to characterize the quasiphase-segregated adsorption of fatty acid and its derivate mixtures from phenyloctane solvent at room temperature by Yablon et al. [16] Stevens and Beebe [17] investigated layer formation of saturated (octadecanoic acid) and unsaturated (elaidic acid $\left.\mathrm{CH}_{3}\left(\mathrm{CH}_{2}\right)_{7} \mathrm{CH}=\mathrm{CH}\left(\mathrm{CH}_{2}\right)_{7} \mathrm{COOH}\right)$ fatty acid mixtures. Mixed monolayers can be used to gain information about dynamic processes that is not available from studies of pure monolayers. Information about the structure and properties of the self-assembled organic monolayers can help in the fabrication of novel molecular electronic devices as well as provide a new experimental method for chemist investigating the kinetics and mechanism of chain reactions [18].

Some seminal research has also focused on the application of ordered long alkyl-chain templates for metal-clusters, nanoparticles deposition. Linearly arranged ligand stabilized $\mathrm{Au}_{55}$ clusters were presented by Hoeppener et al. [19] and $\mathrm{C}_{18} \mathrm{H}_{37} \mathrm{SH} / \mathrm{C}_{14} \mathrm{H}_{29} \mathrm{COOH} / \mathrm{Au}_{55}$ cluster mixture has been dissolved in phenyloctane and added on the HOPG substrate. Gold cluster coverage should be low as the insulating ligand shell, which covers the cluster core, does not participate in the electron tunneling; in other case, the STM imaging is unstable. The results indicate that the distance between gold rows is always multiple of the length of the template forming fatty acid. The metal-line formation is partial, not completely filled with cluster assemblies, and the investigated structures so far are only stable in the liquid environment of the solution. Lei et al. reported the synthesis and assembly of 1-dodecanethiol capped nickel particles using an alkaneassembling monolayer [20].

The aim of the present study is to characterize the fatty acid self-assembled patterns on HOPG and its modification with colloidal nickel nanoparticles from wet chemistry deposition. Scanning tunneling microscopy is used to observe the changes on the solid/liquid interface in the case of fatty acids and fatty acids-Ni NPs surfaces.

\section{Materials and Methods}

2.1. Sample Preparation. Fatty acids were purchased from different companies (octadecanoic acid/stearic acid/- Merck, Fisher Chemicals; oleic acid and elaidic acid, Fluka) and used as received. Lauryl hydroxamic acid $\left(\mathrm{C}_{11} \mathrm{H}_{23}-\mathrm{CO}_{2} \mathrm{NH}_{2}\right)$ was prepared in our laboratory [21]. 1-phenyloctane (SigmaAldrich, 98\%; Acros Organics, 99\%) was used as a solvent. The solvent must be nonpolar to allow the tunneling current to be measured while the tip dips into solution [22]. $10 \mu \mathrm{L}$ drops of the different saturated phenyloctane solutions were transferred to the surface of HOPG (SPI-1 Grade, SPI, USA). Dispersion of Ni-nanoparticles (see Section 2.1.1) was mixed with fatty acids saturated solution.

2.1.1. Synthesis of Ni-Nanoparticles. $\mathrm{Ni}\left(\eta^{4}-\mathrm{C}_{8} \mathrm{H}_{12}\right)_{2}$ (STREM, 98\%) and 1-hexadecylamine (ACROS, 90\%) were used as received; mesitylene (ACROS, 97\%) was dried, degassed, and stored on molecular sieve in the glove box.

A solution of $\mathrm{Ni}\left(\eta^{4}-\mathrm{C}_{8} \mathrm{H}_{12}\right)_{2}\left(0.03 \mathrm{~mol} \mathrm{~L}^{-1}\right)$ and 1hexadecylamine (10 equiv) was dissolved in $3 \mathrm{~mL}$ mesitylene under dry $\mathrm{N}_{2}$; the mixture was heated under stirring to $170^{\circ} \mathrm{C}$ for $30 \mathrm{~min}[23,24]$.

2.2. Molecular Arrangement and Orientation. The morphology of sample surfaces was observed by scanning tunneling microscopy (Pico, Agilent, Molecular Imaging, USA; EasyScan, Nanosurf, Switzerland). STM investigations were performed on the phenyloctane/HOPG interface at room temperature using mechanically cut $\mathrm{W}$ or Pt/Ir-tip. The images were taken during the immersion of the tip into the thin layer of solution. All the images were recorded in the constant-current mode. The specific tunneling parameters are given in the corresponding figure captions. STM images were evaluated with WSxM software [25].

Images from at least five different domains observed on same sample as well as samples from several different days were used to ensure the accuracy and reproducibility. Images were obtained also with different tips to ensure that the images are free from artifacts caused by the tip. Sometimes, after successfully observing the molecular arrays, the underlying graphite lattice was also intentionally imaged, so that the in situ standard for calibration was obtained.

STM-images are discussed only if the measured molecular distances of long alkyl-chain molecules are in good agreement with the theoretical calculations. Only images corresponding to real dimensions of the investigated molecules are presented.

\section{Results and Discussion}

3.1. Direct Deposition of Ni-Nanoparticles on HOPG Surface. Ni NPs are synthesized by decomposition of Ni $\left(\eta^{4}-\mathrm{C}_{8} \mathrm{H}_{12}\right)_{2}$ in presence of an excess of hexadecylamine. Ni NPs are then coated with this amine ligand during the synthesis process and then thoroughfully washed to remove most of the free ligands (Figure 1).

At the initial stage of our experiments, the Ni-nanoparticles were directly deposited on the surface of HOPG from toluene by drop casting method. It was found that the particles are mostly concentrated at the steps of the graphite layers which behave like physical barriers for particles during the drying process (Figure 2). The aggregation of some particles was also observed (Figure 2(c)).

These results confirm that hexadecylamine-capped Ninanoparticles do not display high affinity for graphite. To deposit Ni-nanoparticles on the flat terraces of HOPG and not only at steps, an ordered self-assembled organic template was used.

3.2. Organic Template Formation on the Surface of HOPG. High-resolution STM images were taken about self-assembled fatty acid layers on solid (HOPG)-liquid (phenyloctane) interface. Figure 3 shows the ordered layers of octadecanoic acid. The molecules are arranged in rows with a $90^{\circ}$ angle 


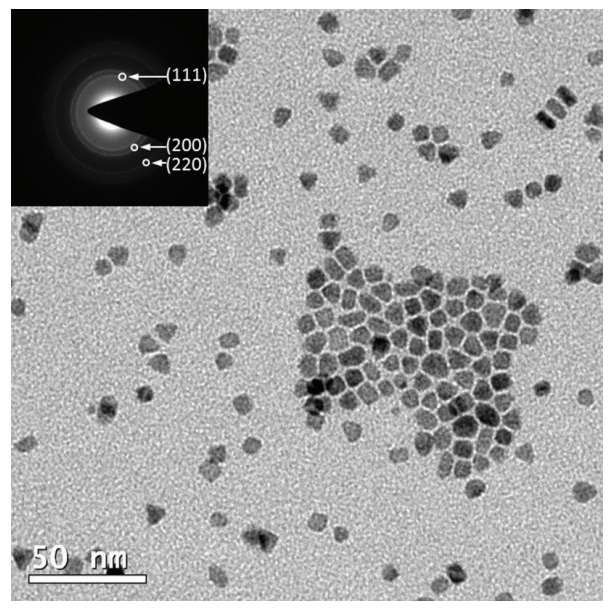

FIGURE 1: TEM image of the Ni-nanoparticles used during the STM investigation.
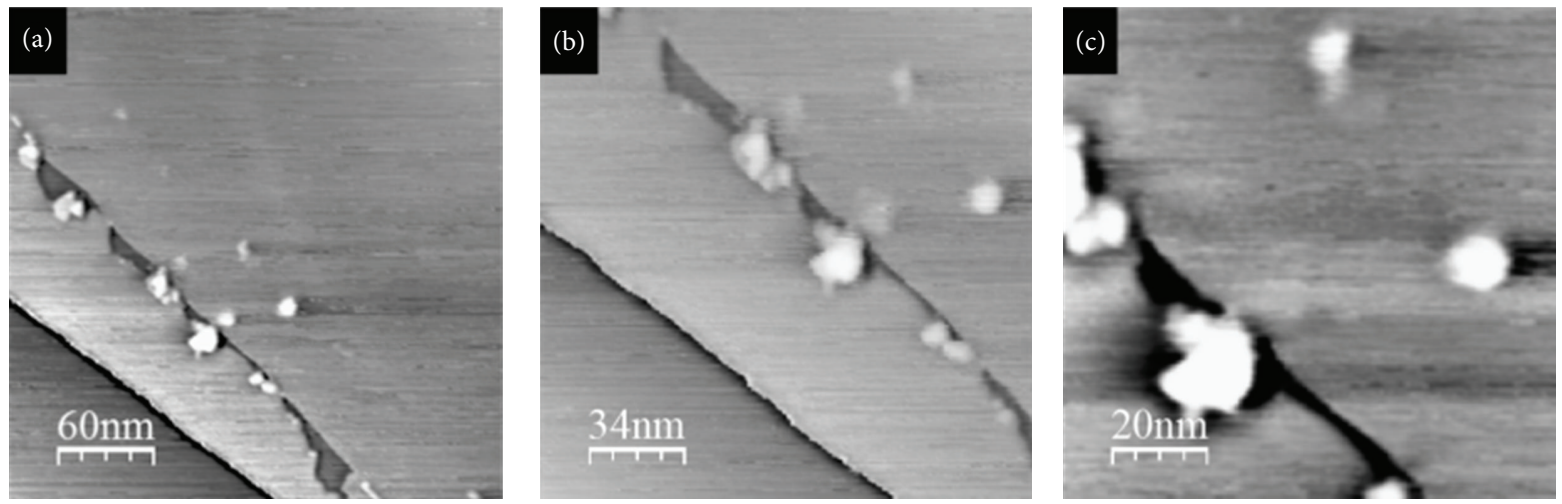

Figure 2: STM image of Ni-nanoparticles at the steps of HOPG ((a) $300 \mathrm{~nm} \times 300 \mathrm{~nm} / i_{t}=1 \mathrm{nA}, V_{\text {bias }}=900 \mathrm{mV} / ;$ (b) $170 \mathrm{~nm} \times 170 \mathrm{~nm} / i_{t}=$ $1 \mathrm{nA}, V_{\text {bias }}=900 \mathrm{mV} /$; (c) $\left.100 \mathrm{~nm} \times 100 \mathrm{~nm} / i_{t}=1 \mathrm{nA}, V_{\text {bias }}=900 \mathrm{mV} /\right)$.

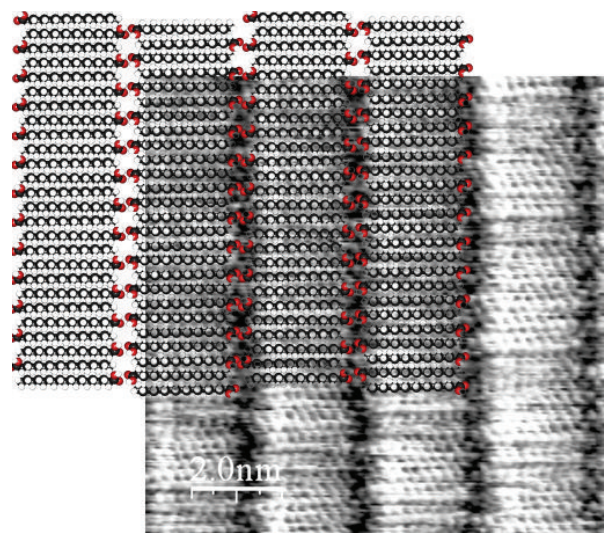

Figure 3: High-resolution $(10 \mathrm{~nm} \times 10 \mathrm{~nm})$ image of ordered octadecanoic acid $/ i_{t}=1 \mathrm{nA}, V_{\text {bias }}=500 \mathrm{mV} /$ on solid/liquid interface and the model.

between the molecular axes and the row direction (the model of the octadecanoic acid layer structure is also visible on Figure 3). This orientation permits hydrogen bonding between the carboxylic functional groups of the molecules in adjacent rows.
The typical periodicity of the nanostructures is $2.1 \pm$ $0.1 \mathrm{~nm}$ (bright, measured parallel to the alkyl-chain) and $0.4 \pm$ $0.1 \mathrm{~nm}$ (dark gap, measured perpendicular to the bright lines) by octadecanoic acid. The results are in good agreement with reported experiments and theoretical calculations (calculated 

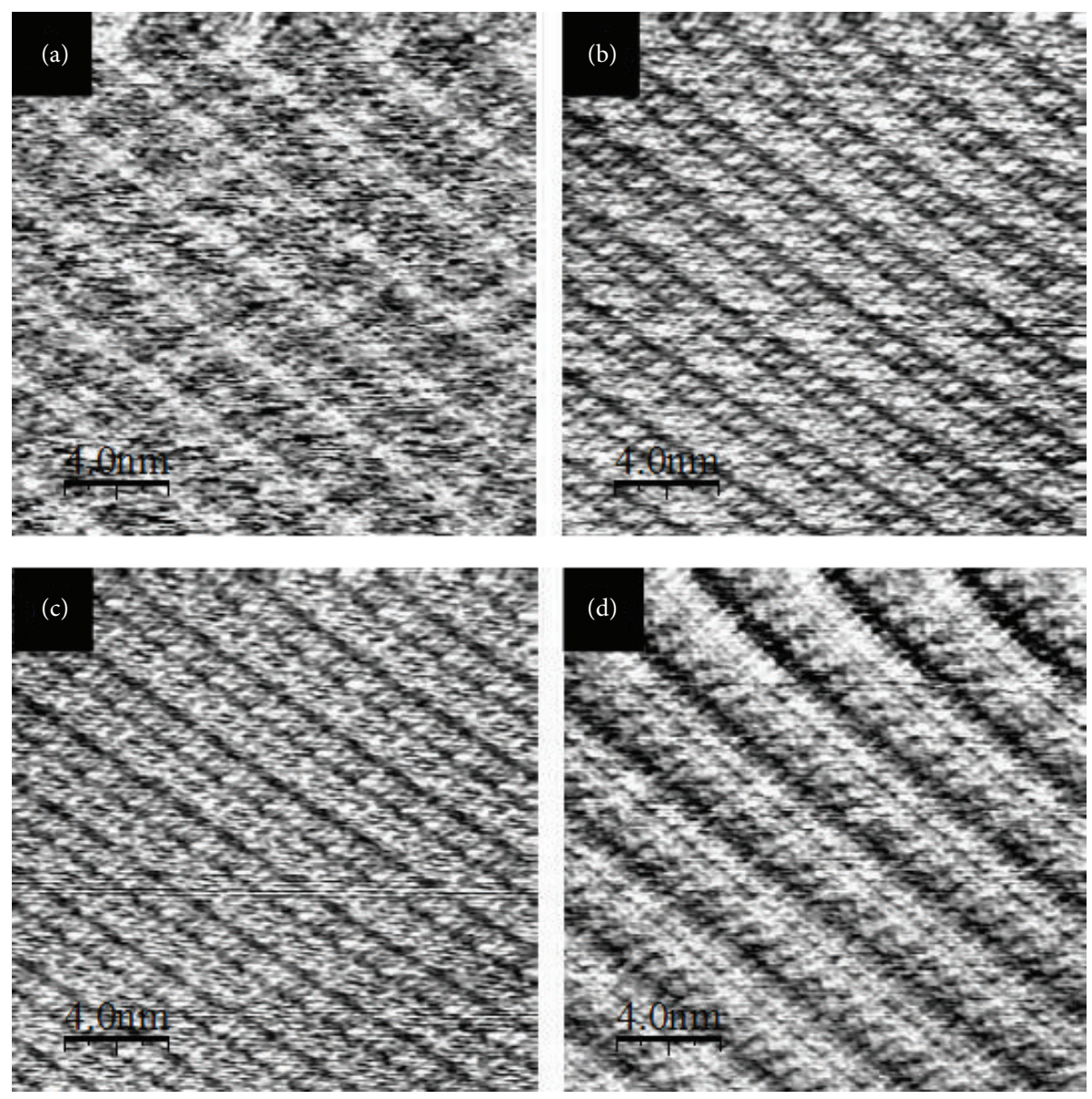

Figure 4: High-resolution $(20 \mathrm{~nm} \times 20 \mathrm{~nm})$ STM images of octadecanoic acid layers taken on the same place of solid/liquid interface by different/ (a) $V_{\text {bias }}=-800 \mathrm{mV}$, (b) $V_{\text {bias }}=-500 \mathrm{mV}$, (c) $V_{\text {bias }}=500 \mathrm{mV}$, and (d) $V_{\text {bias }}=800 \mathrm{mV} /$ bias-potentials, tunneling current by all measurement: $i_{t}=1 \mathrm{nA}$.
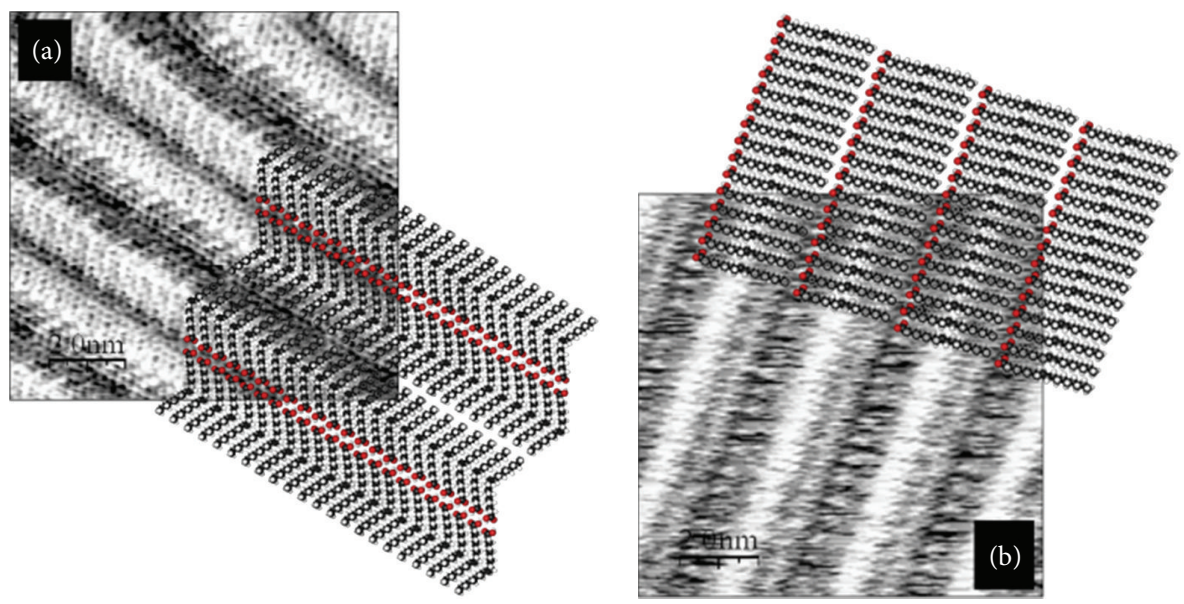

FIGURE 5: "Tilted" and unsaturated fatty acid layers on the solid/liquid interface. High-resolution $(10 \mathrm{~nm} \times 10 \mathrm{~nm}) \mathrm{image}$ of oleic acid/ (a) $i_{t}$ $=1 \mathrm{nA}, V_{\text {bias }}=500 \mathrm{mV} /$ and elaidic acid $/(\mathrm{b}) i_{t}=1 \mathrm{nA}, V_{\text {bias }}=500 \mathrm{mV} /$ on solid/liquid interface and the model of the formed layer.

length of molecules in all trans conformation is $2.13 \mathrm{~nm}$ ). Layered structures found in octadecanoic acids adopt a typical head-to-tail arrangement; the holes (inside the dark gaps) can be interpreted as the visualization of hydrogen bonds between molecules that are hosted in an arrangement in which carboxyl and methylene groups face each other in neighboring rows [10].

Different structures of the self-assembled fatty acid layers are visible on the STM images by changing the parameters of scanning, as it is visible on Figure 4. Same area of the 

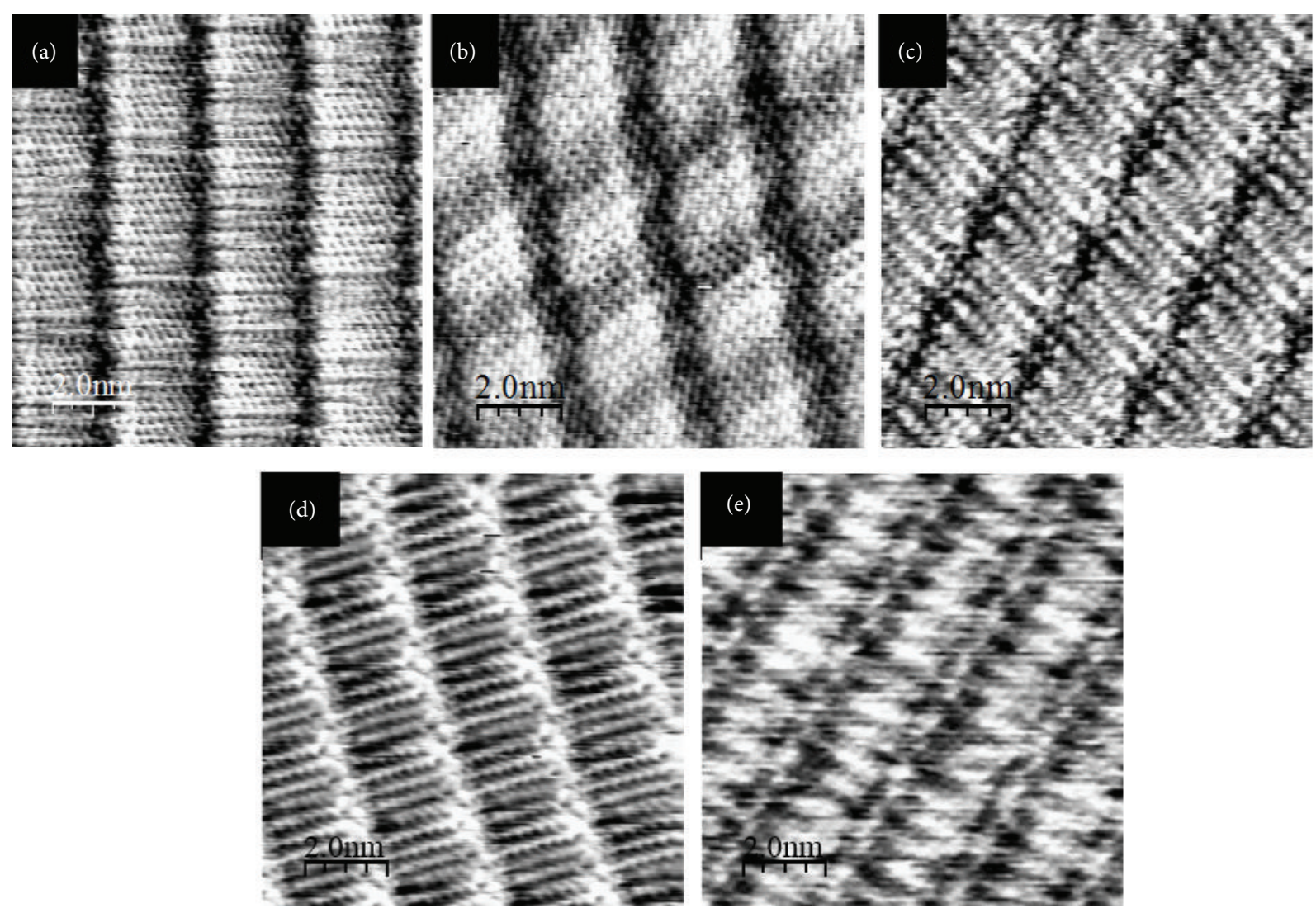

FIGURE 6: Impact of the hydroxamic acid presence on the structure of fatty acid layers. Octadecanoic acid patterns on solid/liquid interface with different structure, depending on the octadecanoic acid and C12N-hydroxamic acid ratio ((a) $1: 0 / i_{t}=1 \mathrm{nA}, V_{\text {bias }}=500 \mathrm{mV} /,(\mathrm{b}) 1: 2 / i_{t}$ $=1 \mathrm{nA}, V_{\text {bias }}=700 \mathrm{mV} /$, (c) $1: 10 / i_{t}=0.4 \mathrm{nA}, V_{\text {bias }}=700 \mathrm{mV} /$, (d) $2: 1 / i_{t}=0.4 \mathrm{nA}, V_{\text {bias }}=700 \mathrm{mV} /$, (e) $\left.3: 1 / i_{t}=1 \mathrm{nA}, V_{\text {bias }}=700 \mathrm{mV} /\right)$ in the phenyloctane solution.
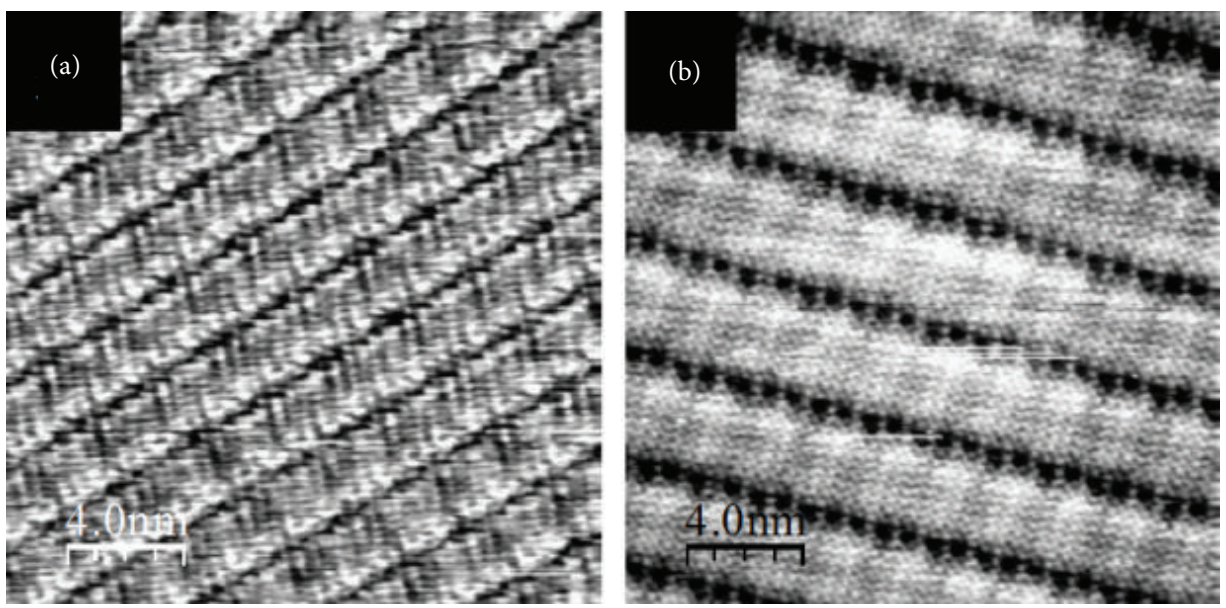

FIGURE 7: Different structures of octadecanoic acid on the phenyloctane/HOPG interface from the solution with 1:10 ratio of fatty and hydroxamic acid $/ i_{t}=0.4 \mathrm{nA}, V_{\text {bias }}=700 \mathrm{mV} /$.

solid/liquid interface on HOPG has been scanned by different bias potentials $(-800 \mathrm{mV},-500 \mathrm{mV}, 500 \mathrm{mV}$, and $800 \mathrm{mV})$. At $-800 \mathrm{mV}$ (Figure $4(\mathrm{a})$ ) and $800 \mathrm{mV}$ (Figure 4(d)), the separated molecules of octadecanoic acid are not visible; the periodicity of the nanostructure is twice compared to the length of the stearic acid molecule (details above in discussion of Figure 3). It means that the bright lines between the darker gaps correspond to the "fusion" of two molecules. At $-500 \mathrm{mV}$ (Figure 4(b)) and $500 \mathrm{mV}$ (Figure 4(c)), all the molecules can be separately identified. 

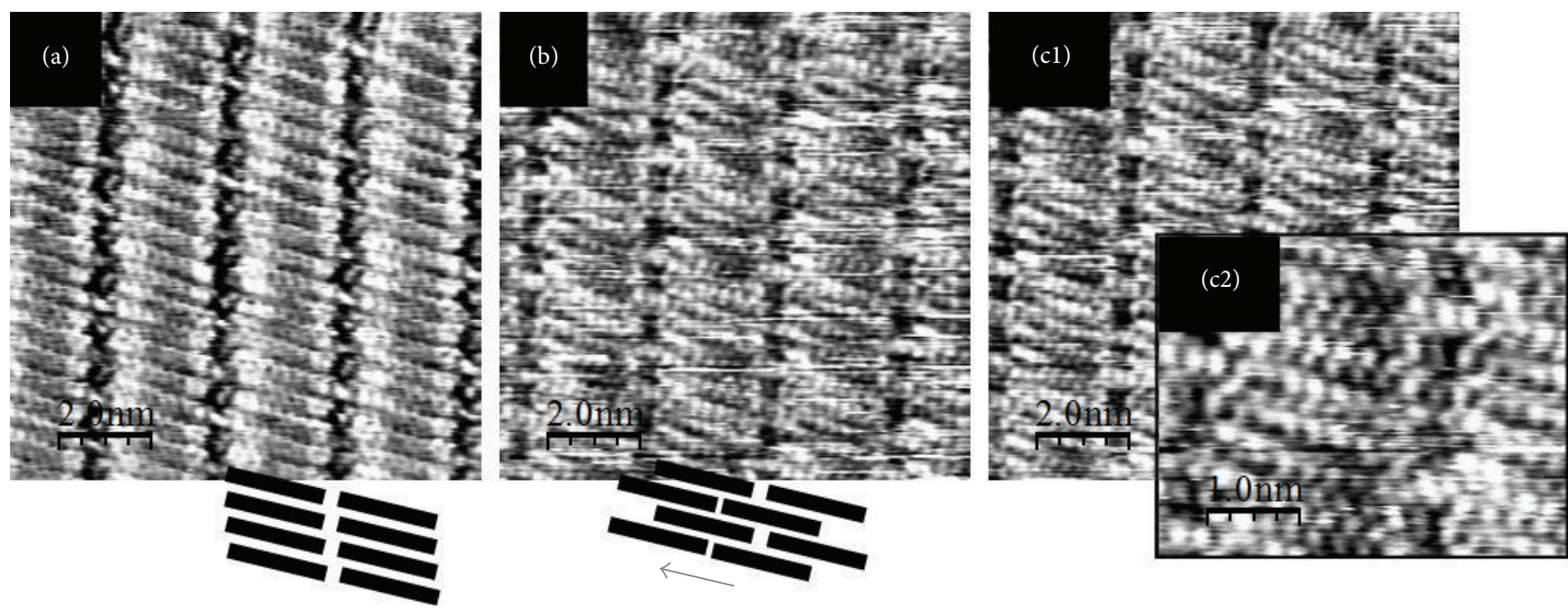

FIGURE 8: Motion of fatty acid molecules on the solid/liquid interface. STM images $\left(10 \mathrm{~nm} \times 10 \mathrm{~nm} / i_{t}=0.4 \mathrm{nA}, V_{\text {bias }}=700 \mathrm{mV} /\right)$ displaying the mobility of fatty acid patterns during scan (scan time: (a) $t=0 \mathrm{~min}$; (b) $t=15 \mathrm{~min}$; (c) $t=30 \mathrm{~min}$ ). $5 \mathrm{~nm} \times 5 \mathrm{~nm} \mathrm{image/(c2)} i_{t}=0.4 \mathrm{nA}$, $V_{\text {bias }}=700 \mathrm{mV}$ of interlocking octadecanoic acid chains.
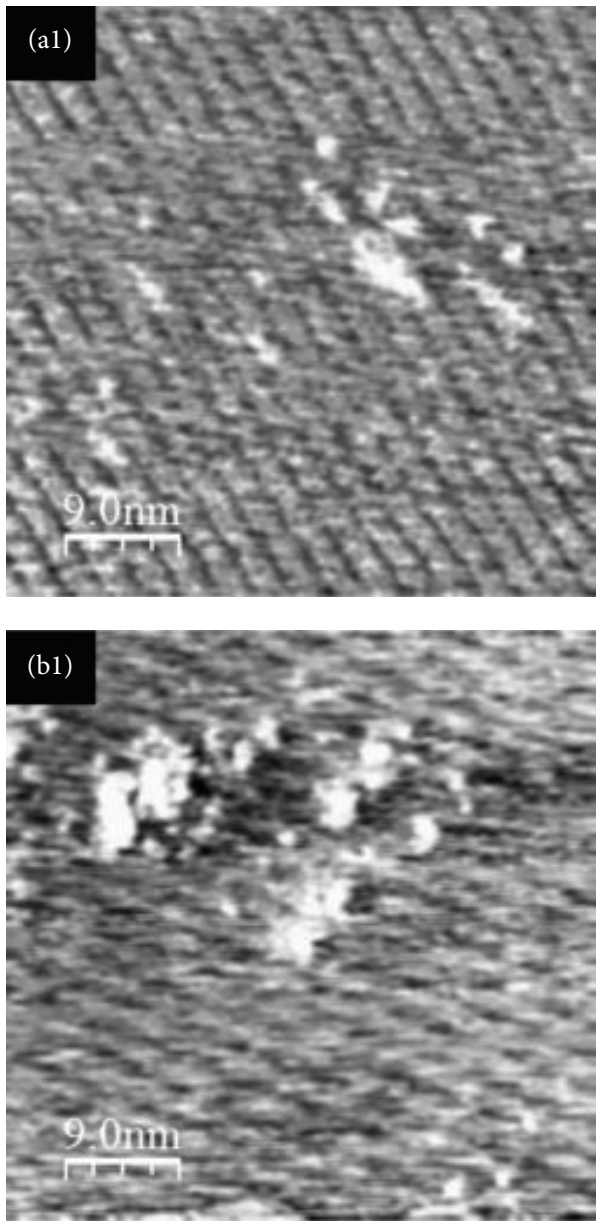
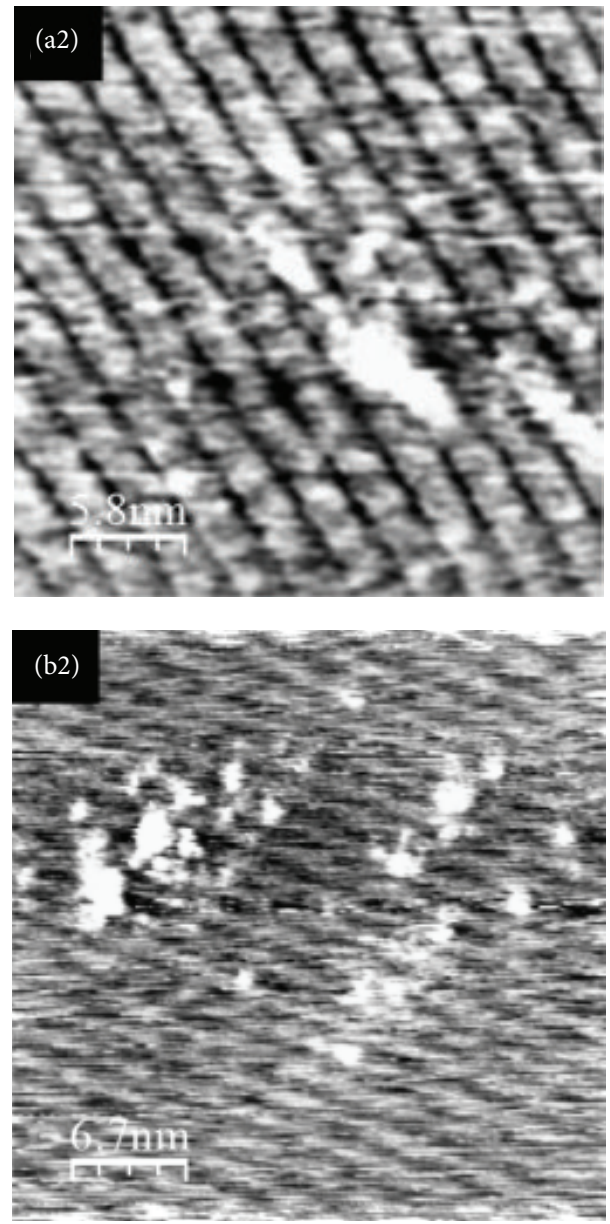

FIGURE 9: STM image of Ni-nanoparticles at two different places on ordered octadecanoic acid array ((a1) $45 \mathrm{~nm} \times 45 \mathrm{~nm},($ a2) $29 \mathrm{~nm} \times$ $29 \mathrm{~nm} / i_{t}=0.5 \mathrm{nA}, V_{\text {bias }}=900 \mathrm{mV} /$; (b1) $45 \mathrm{~nm} \times 45 \mathrm{~nm},\left(\right.$ b2) $33.5 \mathrm{~nm} \times 33.5 \mathrm{~nm} / i_{t}=0.5 \mathrm{nA}, V_{\text {bias }}=900 \mathrm{mV} /$ ). 


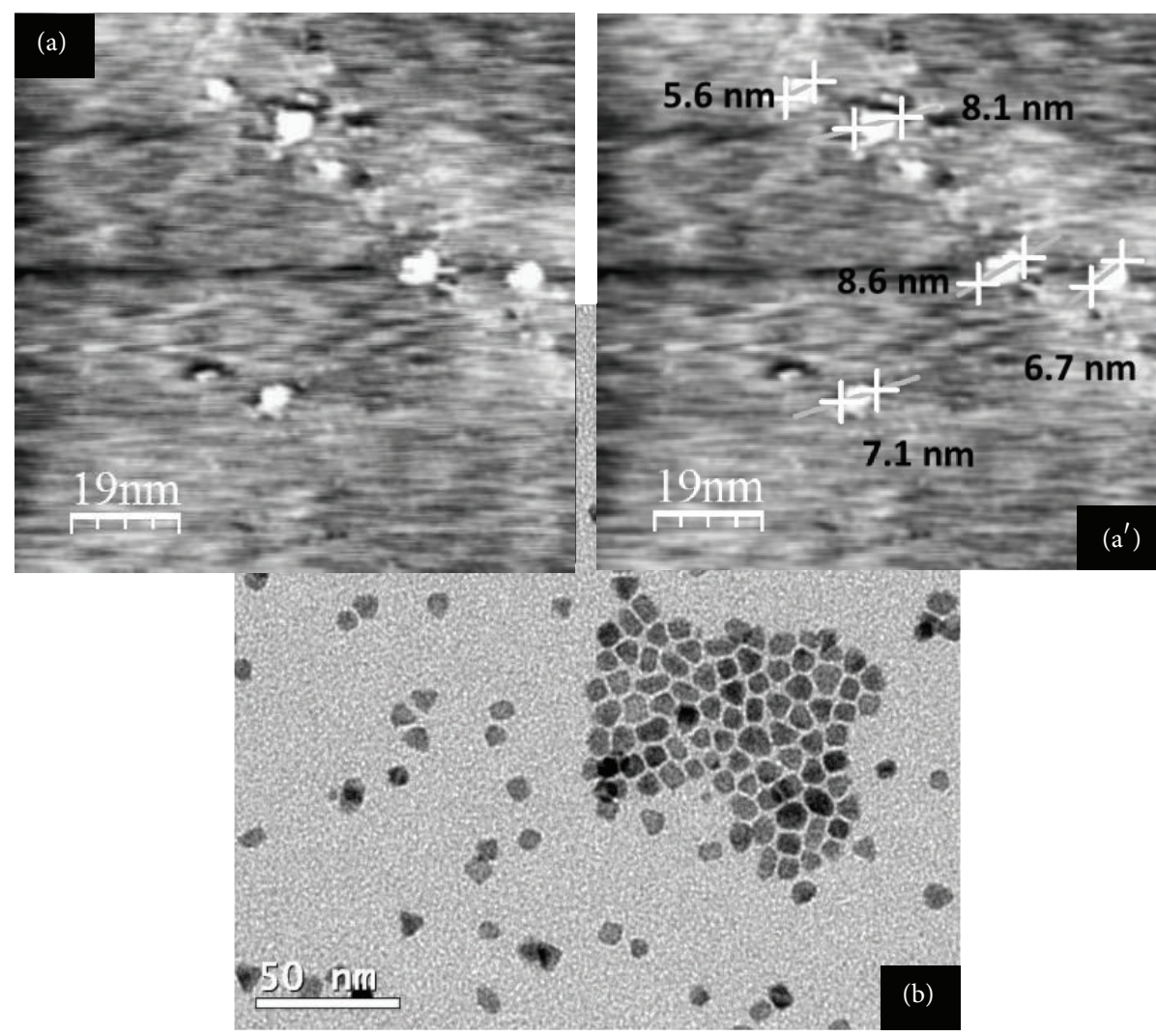

FIGURE 10: STM image of nanoparticles on top of the ordered octadecanoic acid array in line-shape ((a) $95 \mathrm{~nm} \times 95 \mathrm{~nm} / i_{t}=0.5 \mathrm{nA}, V_{\text {bias }}=$ $900 \mathrm{mV} / \mathrm{a}^{\prime}$ ) image (a) with particle size) and the TEM image of the Ni particles.

Template formations with other C18 fatty acids are also tested, namely, oleic acid (cis-9-octadecenoic acid) and elaidic acid (trans-9-octadecenoic acid). As an example for the layer formation of "tilted" fatty acids on solid/liquid interface, the surface treatment of HOPG by oleic acid solution was investigated. On Figure 5(a), the ordered structure, zigzag form of the layer, and the model of the molecular orientation are visible. The layer formation process of the unsaturated fatty acid has been monitored. The double bond in the elaidic acid molecules is visible as a bright spot in the middle of the alkyl-chain on the STM image (Figure 5(b)) due to the higher electron density in the environment of the double bond.

3.3. Modification of Self-Assembled Fatty Acid Patterns. Selfassembled patterns of octadecanoic acid are modified with hydroxamic acid. Drop of fatty and hydroxamic acid mixture is transferred on the surface of HOPG. The change of the molecular pattern can be followed on Figure 6. The molar ratio between octadecanoic and hydroxamic acid is as shown in Figure 6: (a) $1: 0$; (b) $1: 2$; and (c) $1: 10$.

Change of the angle between the direction of the row (dark gaps) and the chain of the molecule is due to the adding of hydroxamic acid into the fatty acid solution. The value of the angle changes from $90^{\circ} \pm 1^{\circ}$ ((a) $\left.1: 0\right)$ to $75^{\circ} \pm 3^{\circ}$ ((b) $1: 2)$ and $69^{\circ} \pm 2^{\circ}$ ((c) $\left.1: 10\right)$. The measured length of the octadecanoic acid chains is in all three cases $2.1 \pm 0.1 \mathrm{~nm}$.
Figure 6(b) reveals an intensity modulation of the contrast in direction parallel to the molecular axes and perpendicular to the row. This modulation or Moiré pattern can be visible as a result of the bulkier headgroups of the acids which require more space as the molecules lie on the graphite, so that the molecules are incommensurate with the graphite substrate along the row direction, resulting in an interference pattern between adsorbed molecules and the substrate [22].

Fatty acid and hydroxamic acid mixtures with higher presence of fatty acid are also investigated (Figures 6(d) and 6(e)). The ratio of octadecanoic and hydroxamic acid is set to (d) $2: 1$ (e) $3: 1$. The measured length of the octadecanoic acid chains is in all three cases around $2.1 \mathrm{~nm}$ (a) $2.1 \pm 0.1 \mathrm{~nm}$, (d) $2.0 \pm 0.1 \mathrm{~nm}$, and (e) $2.1 \pm 0.1 \mathrm{~nm}$. Change of the angle between the direction of the row (dark gaps) and the chain of the molecule is negligible in the case of 1:0 (Figure 6(a)$90^{\circ} \pm 1^{\circ}$ ) and $2: 1$ (Figure $\left.6(\mathrm{~d})-89^{\circ} \pm 1^{\circ}\right)$. Small decrease of the angle value is found with the $3: 1$ ratio sample (Figure 6(e)$82^{\circ} \pm 1^{\circ}$ ). On the basis of the presented STM images, one can conclude that adding of hydroxamic acids in higher amount to fatty acid solutions results in the change of the selfassembled pattern formed on the solid/liquid interface.

Using 1:10 molecular ratio of fatty and hydroxamic acid, two typical structures of the covering layer are observed: one with typical periodicity of $2.1 \pm 0.1 \mathrm{~nm}$ and $69^{\circ} \pm 2^{\circ}$ angle (Figure 7(a)) and the second with $3.6 \pm 0.2 \mathrm{~nm}$ and $89^{\circ} \pm 1^{\circ}$ angle (Figure 7(b)). 

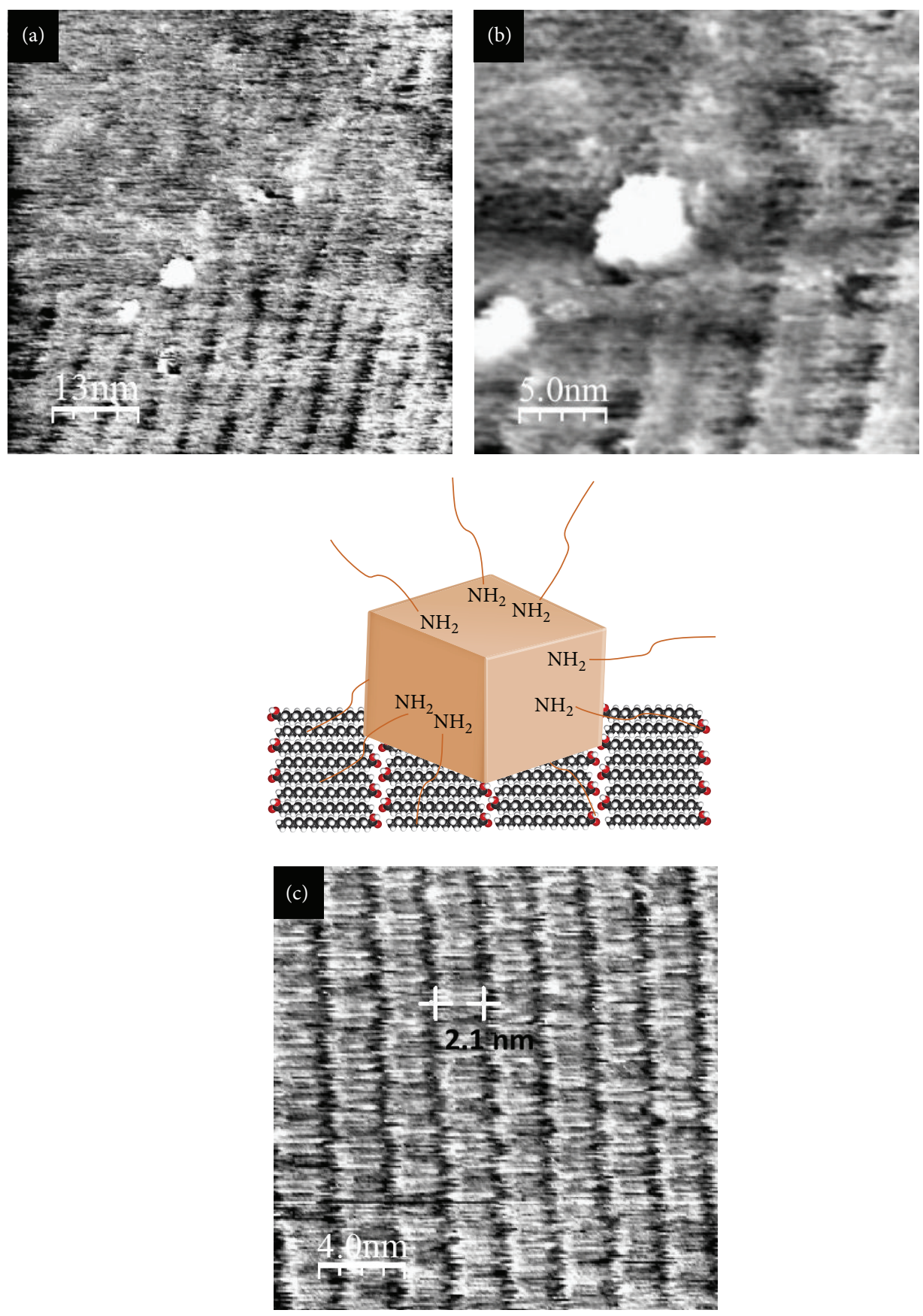

FIGURE 11: Schematic illustration of molecular level bonding mechanism between Ni particle and the fatty acid monolayer. STM image of nanoparticles on the top of the ordered octadecanoic acid array ((a) $\left.65 \mathrm{~nm} \times 65 \mathrm{~nm} / i_{t}=0.5 \mathrm{nA}, V_{\text {bias }}=900 \mathrm{mV} /\right)$. High resolution STM image of individual Ni particle $\left((\mathrm{b}) 25 \mathrm{~nm} \times 25 \mathrm{~nm} / i_{t}=0.5 \mathrm{nA}, V_{\text {bias }}=900 \mathrm{mV} /\right)$ and the ordered fatty acid template on the same sample $((\mathrm{c}) 20 \mathrm{~nm}$ $\left.\times 20 \mathrm{~nm} / i_{t}=0.5 \mathrm{nA}, V_{\text {bias }}=900 \mathrm{mV} /\right)$.

This result can be connected to the fact that the formation of the ordered structure is a steady-state process. During the scan of the previously introduced surface, we observe the mobility of the molecules (Figure 8) corresponding to the results presented in the literature about the molecular motion of fatty acids on solid/liquid interface [26]. The octadecanoic acid molecules are interlocking (Figures $8(\mathrm{~b})$ and $8(\mathrm{cl})$ ) to each other as it is visible on the high resolution image also (Figure 8(c2)).

3.4. Template Directed Simultaneous Deposition of Ni-Nanoparticles. Wet chemical deposition of colloidal Ni-nanoparticles parallel with ordered array formation of octadecanoic acid molecules on solid/liquid interface is monitored 
with STM. Indeed, the template effect on metal deposition can only be tested by a colloidal approach and not by gas phase deposition (PVD, ALD...) since the molecular array is formed and stabilized at the solid/liquid interface.

The local density of the physisorbed Ni-layer is inhomogeneous as displayed on the Figure 9. Line or small "island" formation of metal particles on top of the organic layer is monitored. The images (Figures 9(a) and 9(b)) are taken on different places of the samples.

The size distribution (Figure 10) of particles $(7.2 \pm 1.2 \mathrm{~nm}$ ) corresponds to the size range measured on TEM pictures.

From the presented STM images, it is clear that the metal nanoparticles are in direct contact with the bands formed by fatty acids (Figure 11(a)). Particles connection with the surface may be attributed to the attractive van der Waals interactions between the hydrophobic hexadecylamine outer shell of nickel particles and the ordered octadecanoic acid layer on HOPG [20]. In the case of Figures 11(a) and 11(b), the template bands are twice wider than the single length of octadecanoic acid $(2.1 \mathrm{~nm})$. This effect has been discussed at Figure 7 and can be connected to the steady-state formation process of the ordered fatty acid structure. High resolution STM image of the template (similar to the first experiments presented in subchapter Organic template formation on the surface of HOPG of this research paper) is taken on the same sample with same scanning parameters (Figure 11(c)).

Next to the simultaneous $\mathrm{Ni}$ colloidal deposition, two other coating techniques are investigated. In the case of two-step process ((1) organic template layer formation on HOPG and (2) deposition of Ni-nanoparticles) and in-situ $\mathrm{Ni}$-nanoparticle synthesis (from $\mathrm{Ni}(\mathrm{COD})_{2}$ precursor in the presence of amine in phenyloctane solution based on our previous papers $[23,27]$ ) on the substrate, good quality STM images of metal nanoparticles cannot be obtained. Based on this experience, we can conclude that self-assembly of the molecular template monolayer directs the simultaneous wet chemical metal deposition and the use of colloidal solution (fatty acid + Ni-nanoparticles in phenyloctane) is essential.

\section{Summary}

The objective of the present studies is to investigate the layer formation of self-assembling molecules of fatty acids and simultaneous Ni deposition on top of the ordered long alkylchain layers. The thin film formation has been followed by scanning tunneling microscopy. Ordered structure of octadecanoic acid is observed, and layered structure represents the model of a typical head-to-tail arrangement. The STM images prove the presence of molecular motion on solid/liquid interface. It is found that the structure (angle between the direction of the row and the chain of the molecule) of the formed layer changes by the presence of hydroxamic acid (rate of fatty and hydroxamic acid 1:2,1:10) in the treatment solution of the fatty acids. Directed deposition of $\mathrm{Ni}$-nanoparticles is observed on top of the organic template and the particles sit on the tails of long chain carboxylic acid, and particles tend to form chain like aggregates.

\section{Conflict of Interests}

The authors declare that there is no conflict of interests regarding the publication of this paper.

\section{Acknowledgments}

Authors would like to thank Dr. Zsófia Keresztes, Dr. Judit Telegdi, Ildikó Kék, and Dr. Imre Bakó for helpful discussion.

\section{References}

[1] A. N. Shipway, E. Katz, and I. Willner, "Nanoparticle arrays on surfaces for electronic, optical, and sensor applications," ChemPhysChem, vol. 1, no. 1, pp. 18-52, 2000.

[2] S. de Feyter, A. Gesquire, M. M. Abdel-Mottaleb et al., "Scanning tunneling microscopy: a unique tool in the study of chirality, dynamics, and reactivity in physisorbed organic monolayers," Accounts of Chemical Research, vol. 33, no. 8, pp. 520-531, 2000.

[3] B. Zou, K. Dreger, C. Mück-Lichtenfeld et al., "Simple and complex lattices of $\mathrm{N}$-alkyl fatty acid amides on a highly oriented pyrolytic graphite surface," Langmuir, vol. 21, no. 4, pp. 1364-1370, 2005.

[4] Y. Kuwahara, G. Zhang, J. Wu, M. Akai-Kasaya, A. Saito, and M. Aono, "Scanning tunneling microscopy observation of binary monolayers deposited by horizontal lifting method," RIKEN Review, vol. 45, pp. 6-8, 2002.

[5] Q. Chen, H.-J. Yan, C.-J. Yan et al., "STM investigation of the dependence of alkane and alkane $\left(\mathrm{C}_{18} \mathrm{H}_{38}, \mathrm{C}_{19} \mathrm{H}_{40}\right)$ derivatives self-assembly on molecular chemical structure on HOPG surface," Surface Science, vol. 602, no. 6, pp. 1256-1266, 2008.

[6] S. de Feyter and F. C. de Schryver, "Two-dimensional supramolecular self-assembly probed by scanning tunneling microscopy," Chemical Society Reviews, vol. 32, no. 3, pp. 139-150, 2003.

[7] B. Venkataraman, G. W. Flynn, J. L. Wilbur, J. P. Folkers, and G. M. Whitesides, "Differentiating functional groups with the scanning tunneling microscope," The Journal of Physical Chemistry, vol. 99, no. 21, pp. 8684-8689, 1995.

[8] D. M. Cyr, B. Venkataraman, G. W. Flynn, A. Black, and G. M. Whitesides, "Functional group identification in scanning tunneling microscopy of molecular adsorbates," The Journal of Physical Chemistry, vol. 100, no. 32, pp. 13747-13759, 1996.

[9] I. De Cat, C. Gobbo, B. Van Averbeke, R. Lazzaroni, S. De Feyter, and J. Van Esch, "Controlling the position of functional groups at the liquid/solid interface: impact of molecular symmetry and chirality," Journal of the American Chemical Society, vol. 133, no. 51, pp. 20942-20950, 2011.

[10] S. Hoeppener, L. Chi, and H. Fuchs, "Molecular arrangement of fatty acids at the solid-liquid interface visualized by chemical decoration," ChemPhysChem, vol. 4, no. 5, pp. 494-498, 2003.

[11] M. Hibino, A. Sumi, and I. Hatta, "Scanning tunnelling microscopy study on dynamic structural formation in mixed fatty-acid monolayers at liquid/graphite interface," Thin Solid Films, vol. 281-282, no. 1-2, pp. 594-597, 1996.

[12] M. Hibino, A. Sumi, H. Tsuchiya, and I. Hatta, "Microscopic origin of the odd-even effect in monolayer of fatty acids formed on a graphite surface by scanning tunneling microscopy," Journal of Physical Chemistry B, vol. 102, no. 23, pp. 4544-4547, 1998. 
[13] D. Wintgens, D. G. Yablon, and G. W. Flynn, "Packing of $\mathrm{HO}\left(\mathrm{CH}_{2}\right)_{14} \mathrm{COOH}$ and $\mathrm{HO}\left(\mathrm{CH}_{2}\right)_{15} \mathrm{COOH}$ on graphite at the liquid-solid interface observed by scanning tunneling microscopy: Methylene unit direction of self-assembly structures," Journal of Physical Chemistry B, vol. 107, no. 1, pp. 173-179, 2003.

[14] F. Tao, "Nanoscale surface chemistry in self- and directedassembly of organic molecules on solid surfaces and synthesis of nanostructured organic architectures," Pure and Applied Chemistry, vol. 80, no. 1, pp. 45-57, 2008.

[15] A. K. Bickerstaffe, N. P. Cheah, S. M. Clarke et al., "The crystalline structures of carboxylic acid monolayers adsorbed on graphite," The Journal of Physical Chemistry B, vol. 110, no. 11, pp. 5570-5575, 2006.

[16] D. G. Yablon, D. Ertas, H. Fang, and G. W. Flynn, "An STM investigation of the adsorption of mixtures of fatty acids and substituted acids at the solution-graphite interface," Israel Journal of Chemistry, vol. 43, no. 3-4, pp. 383-392, 2003.

[17] F. Stevens and T. P. Beebe Jr., "Dynamical exchange behavior in organic monolayers studied by STM analysis of labeled mixtures," Langmuir, vol. 15, no. 20, pp. 6884-6889, 1999.

[18] Y. Okawa and M. Aono, "Nanoscale wiring by controlled chain polymerization," Surface Science, vol. 514, no. 1-3, pp. 41-47, 2002.

[19] S. Hoeppener, L. Chi, and H. Fuchs, "Formation of $\mathrm{Au}_{55}$ strands on a molecular template at the solid-liquid interface," Nano Letters, vol. 2, no. 5, pp. 459-463, 2002.

[20] S. B. Lei, C. Wang, S. X. Yin, L. J. Wan, and C. L. Bai, "Assembling nanometer nickel particles into ordered arrays," ChemPhysChem, vol. 4, no. 10, pp. 1114-1117, 2003.

[21] J. Telegdi, T. Rigó, and E. Kálmán, "Molecular layers of hydroxamic acids in copper corrosion inhibition," Journal of Electroanalytical Chemistry, vol. 582, no. 1-2, pp. 191-201, 2005.

[22] D. M. Cyr, B. Venkataraman, and G. W. Flynn, "STM investigations of organic molecules physisorbed at the liquid-solid interface," Chemistry of Materials, vol. 8, no. 8, pp. 1600-1615, 1996.

[23] M. Shviro and D. Zitoun, "Low temperature, template-free route to nickel thin films and nanowires," Nanoscale, vol. 4, no. 3, pp. 762-767, 2012.

[24] M. Shviro and D. Zitoun, "Nickel nanocrystals: Fast synthesis of cubes, pyramids and tetrapods," RSC Advances, vol. 3, no. 5, pp. 1380-1387, 2013.

[25] I. Horcas, R. Fernández, J. M. Gómez-Rodríguez, J. Colchero, J. Gómez-Herrero, and A. M. Baro, "WSXM: a software for scanning probe microscopy and a tool for nanotechnology," Review of Scientific Instruments, vol. 78, no. 1, Article ID 013705, 2007.

[26] M. Hibino, A. Sumi, and I. Hatta, "Molecular motion at domain boundaries in fatty acid monolayers on graphite observed by scanning tunneling microscopy," Thin Solid Films, vol. 273, no. 1-2, pp. 272-278, 1996.

[27] M. Shviro, A. Paszternák, A. Chelly, and D. Zitoun, "Zigzagshaped nickel nanowires via organometallic template-free route," Journal of Nanoparticle Research, vol. 15, no. 8, article 1823, 2013. 

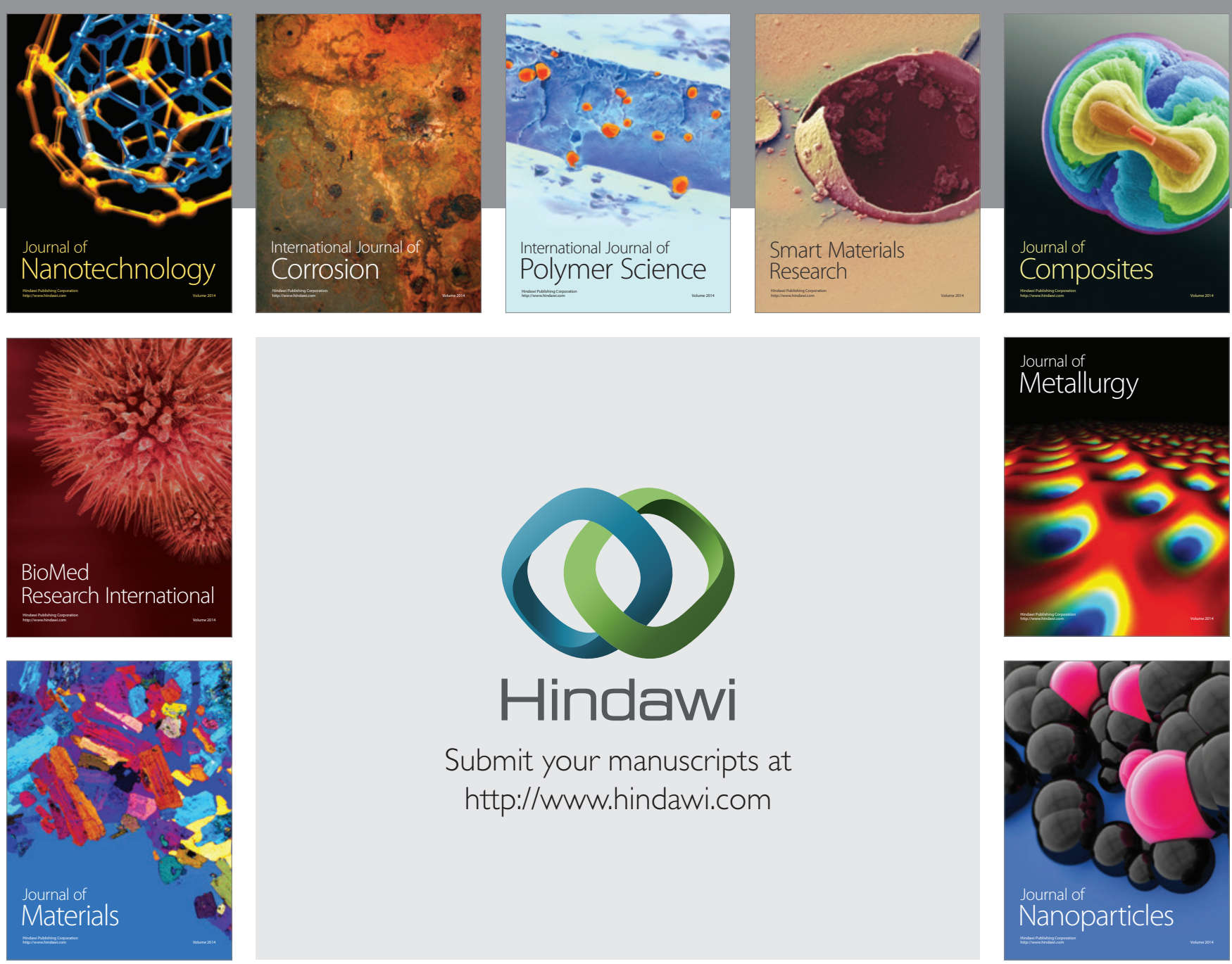

Submit your manuscripts at http://www.hindawi.com
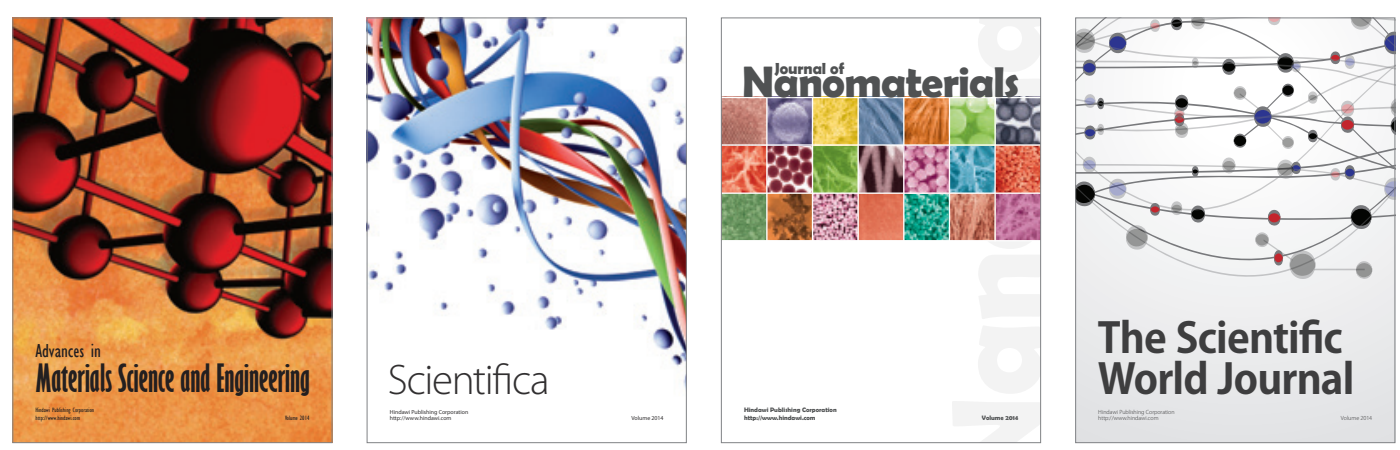

\section{The Scientific World Journal}
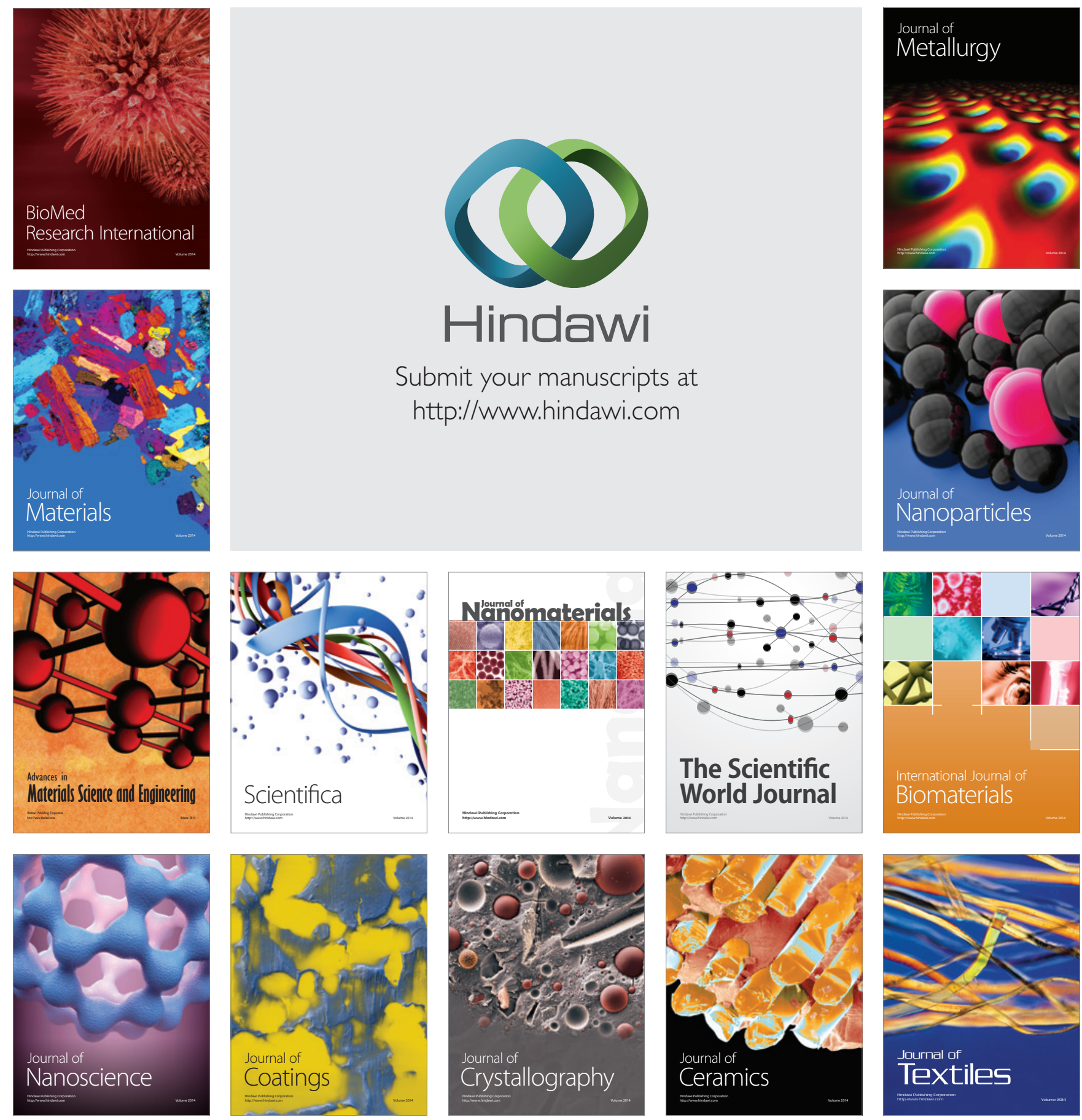